\title{
Erratum to: Transvaginal hybrid NOTES cholecystectomy-results of a randomized clinical trial after 6 months
}

Dirk Rolf Bulian ${ }^{1} \cdot$ Jurgen Knuth $^{1,2} \cdot$ Nicola Cerasani $^{1} \cdot$ Jonas Lange $^{1}$ •

Michael Alfred Ströhlein ${ }^{1}$ Axel Sauerwald ${ }^{3}$. Markus Maria Heiss ${ }^{1}$

Published online: 2 July 2016

(C) Springer-Verlag Berlin Heidelberg 2016

Erratum to: Langenbecks Arch Surg (2014) 399:717-724

DOI: 10.1007/s00423-014-1218-2

The original version of this article unfortunately contained a mistake. The ClinicalTrials.gov identifier found in the Abstract and Introduction section is missing a final digit. The correct digits are NCT01685775.

The online version of the original article can be found at http://dx.doi. org/10.1007/s00423-014-1218-2.

Dirk Rolf Bulian

buliand@kliniken-koeln.de

1 Department of Abdominal, Vascular and Transplant Surgery, Cologne-Merheim Medical Center, Witten/Herdecke University, Ostmerheimer Strasse 200, 51109 Cologne, Germany

2 Department of General, Visceral, Vascular and Thoracic Surgery, Clinic of Kempten, Robert-Weixler-Strasse 50,

87439 Kempten, Germany

3 Department for Obstetrics and Gynecology, Holweide Hospital, Neufelder Strasse 32, 51067 Cologne, Germany 